\title{
Enzyme Activated Gold Nanoparticles for Versatile Site-Selective Bioconjugation
}

\author{
Alexandra V. Ramsey, ${ }^{\mathrm{a}}$ Amanda J. Bischoff, ${ }^{\mathrm{a}}$ and Matthew B. Francis ${ }^{\mathrm{a}, \mathrm{b}}$ \\ ${ }^{a}$ Department of Chemistry, University of California, Berkeley, California 94720, United States \\ ${ }^{b}$ Molecular Biophysics and Integrated Bioimaging Division, Lawrence Berkeley National Laboratories, Berkeley, California \\ 94720, United States
}

Supporting Information

Table of Contents

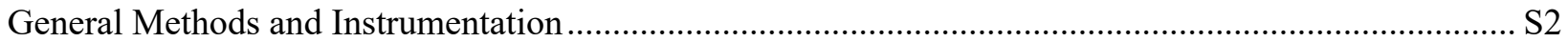

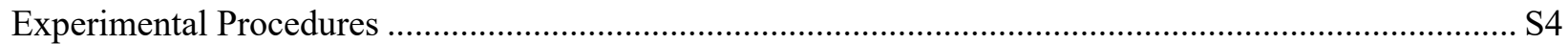

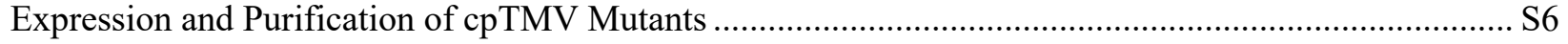

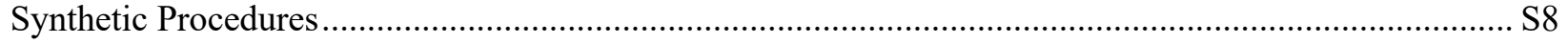

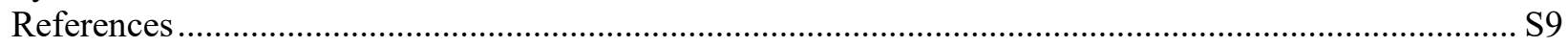

Figure S1. Characterization of phenol- and methoxy-AuNPs ......................................................... S10

Figure S2. Screen of oxidative coupling reaction time and tyrosinase concentration ........................... S11

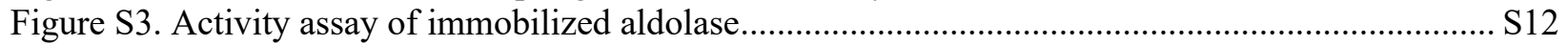

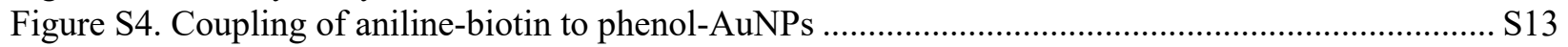

Figure S5. Concentration screen with lower concentrations of DNA ................................................. S14

Figure S6. Quantification of DNA conjugated to phenol-AuNPs (400 nM) ....................................... S15

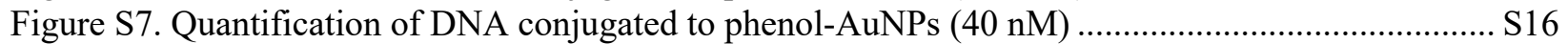

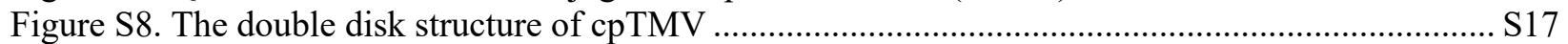

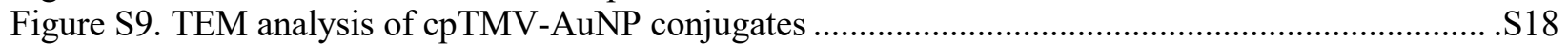

Figure S10. cpTMV-S23C-S65pAF-OG488 and cpTMV-S65pAF-Q101C-OG488 characterization by

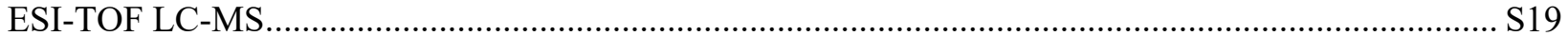

Figure S11. Fluorescent measurements of OG488 conjugated to cpTMV-S65pAF-Q101C ................ S20

Figure S12. Characterization of purified cpTMV-S65pAF, cpTMV-S23C-S65pAF, and cpTMV-S65pAF-

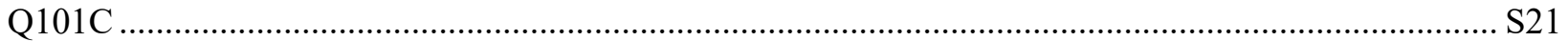

Figure S13. Characterization of cpTMV protein assembly state ................................................... S22

Figure S14. Characterization of lipoic acid-NHS via ${ }^{1} \mathrm{H}$ NMR ….................................................. S23

Figure S15. Characterization of thiol-PEG5k-phenol via ${ }^{1}$ H NMR ....................................................... S24 


\section{General Methods and Instrumentation}

Unless noted otherwise, all reagents were obtained from commercial sources and used without further purification. Amine-PEG5k-valeric acid was purchased from Laysan Bio (Arab, AL). Tyrosinase isolated from Agaricus bisporus (abTyr), aldolase isolated from rabbit muscle, glyceraldehyde-3-phosphate dehydrogenase from rabbit muscle (GAPDH), fructose 1,6-bisphosphate (FBP), all DNA sequences, bis $(p$ sulfonatophenyl)phenylphosphine dihydrate dipotassium salt (BSPP), poly(ethylene glycol) methyl ether thiol (average $\mathrm{M}_{\mathrm{n}}=2,000$, thiol-PEG2k-methoxy), potassium cyanide $(\mathrm{KCN})$, lipoic acid, aniline, tropolone, tyramine, and 4-(2-aminoethyl)aniline were purchased from Sigma-Aldrich (St. Louis, MO). Streptavidin (Texas Red conjugate), EZ-Link NHS-PEG4-biotin, Oregon Green 488 maleimide, and QuantiT OliGreen ssDNA Assay Kit were purchased from Thermo Fisher (Waltham, MA). Unconjugated gold colloids (AuNPs, $5 \mathrm{~nm}$ ) were purchased from Ted Pella, Inc. (Redding, CA). Pro-sfGFP ${ }^{1}$ and sfGFPY200C ${ }^{2}$ were expressed and purified as previously reported. $\mathrm{NAD}^{+}$and spin concentrators with 10 and 100 kDa molecular weight cutoffs (MWCO) were purchased from EMD Millipore (Billerica, MA). Doubly distilled water $\left(\mathrm{ddH}_{2} \mathrm{O}\right)$ was obtained from a Millipore purification system.

$U V$-vis Spectroscopy. Concentrations of AuNP solutions were determined with a Thermo Scientific Nanodrop 1000.

Gel Analyses. Native agarose gel electrophoresis was carried out with 1\% agarose gels and 1x TBE buffer. Prior to loading, samples were mixed with $50 \%$ glycerol in a ratio of $2: 1$ sample:50\% glycerol. Gels were run at $60 \mathrm{~V}$ for either 60 or $90 \mathrm{~min}$. Protein gels were stained with Coomassie Brilliant Blue. For imaging (both with and without stain), gels were placed on a white gel tray and imaged in a light box with an iPhone 8. Gels containing SYBR Safe stain ( $6 \mu \mathrm{L}$ added to $60 \mathrm{~mL}$ gels) were imaged under UV light in a Bio-Rad Gel Doc EZ System.

Dynamic Light Scattering. DLS measurements were carried out with a Malvern Panalytical Zetasizer Nano ZS. Measurements were carried out in triplicate at AuNP concentrations of $5-10 \mathrm{nM}$ in $\mathrm{ddH}_{2} \mathrm{O}$ at $25{ }^{\circ} \mathrm{C}$ or protein concentrations of $0.2-1.0 \mathrm{mg} / \mathrm{mL}$ in $10 \mathrm{mM}$ sodium phosphate buffer at $\mathrm{pH} 7.2$ and $25^{\circ} \mathrm{C}$.

Transmission Electron Microscopy. TEM analysis of cpTMV-AuNP conjugates and cpTMV mutants was carried out at the Berkeley Electron Microscopy Lab with an FEI Tecnai 12 transmission electron microscope with $100 \mathrm{kV}$ accelerating voltage. Samples were prepared for analysis by applying analyte solution $(5 \mu \mathrm{L}$ of $150 \mathrm{nM}$ cpTMV-AuNPs in $20 \mathrm{mM}$ sodium phosphate buffer at $\mathrm{pH} 6.5$ or $5 \mu \mathrm{L}$ of $0.2-1$ $\mathrm{mg} / \mathrm{mL}$ cpTMV in $10 \mathrm{mM}$ sodium phosphate buffer at $\mathrm{pH} 7.2$ ) to carbon-coated copper grids for 2 min. For cpTMV-AuNPs, sample application was followed by rinsing in $3 \times 10 \mu \mathrm{L}$ of $\mathrm{ddH}_{2} \mathrm{O}$ and then staining with $5 \mu \mathrm{L} 1 \%$ aqueous uranyl acetate; samples were left in the stain for $1 \mathrm{~min}$. For characterization of cpTMV mutants, sample application was followed by rinsing in $4 \times 10 \mu \mathrm{L}$ droplets of $1 \%$ aqueous uranyl acetate; samples were left in the final droplet for $1 \mathrm{~min}$.

Fluorometry. Fluorescence measurements were obtained with a Fluoromax-4 Spectrofluorometer (HORIBA Scientific). Samples were excited at $485 \mathrm{~nm}$ with a $5 \mathrm{~nm}$ window, and emission was monitored from 500 to $700 \mathrm{~nm}$.

NMR. ${ }^{1} \mathrm{H}$ spectra were recorded on either a Bruker AV-300 (300 MHz) or a Bruker AV-600 (600 MHz) spectrometer.

Electrospray Ionization Time of Flight Liquid Chromatography Mass Spectrometry (ESI-TOF LC-MS). Acetonitrile (Optima grade, 99.9\%, Fisher, Waltham, MA), formic acid (1 mL ampules, 99+\%, Pierce, Rockford, IL), and water purified to a resistivity of $18.2 \mathrm{M} \Omega \cdot \mathrm{cm}$ (at $25^{\circ} \mathrm{C}$ ) using a Milli-Q Gradient ultrapure water purification system (Millipore, Billerica, MA) were used to prepare mobile phase solvents 
for LC-MS. Electrospray ionization mass spectrometry (ESI-MS) of protein bioconjugates was performed using an Agilent 1260 series liquid chromatograph outfitted with an Agilent 6224 time-of-flight (TOF) LCMS system (Santa Clara, CA). The LC was equipped with a Proswift RP-4H (monolithic phenyl, $1.0 \mathrm{~mm}$ $\times 50 \mathrm{~mm}$, Dionex) analytical column. Solvent A was $99.9 \%$ water $/ 0.1 \%$ formic acid (v/v) and solvent B was $99.9 \%$ acetonitrile $/ 0.1 \%$ formic acid (v/v). Each sample was prepared for analysis by desalting and spinning through an $0.22 \mu \mathrm{m}$ cellulose acetate centrifugal spin filter, and then $8 \mu \mathrm{L}$ of $10 \mu \mathrm{M}$ protein was injected onto the column. Following sample injection, a 5-100\% B elution gradient was run at a flow rate of $0.30 \mathrm{~mL} / \mathrm{min}$ over $8 \mathrm{~min}$. Data were collected and analyzed by deconvolution of the entire elution profile (using Agilent Mass Hunter Qualitative Analysis B.05.00) in order to provide reconstructed mass spectra that were representative of the entire sample. Spectra were analyzed with open source Chartograph software (www.chartograph.com).

High Performance Liquid Chromatography (HPLC). HPLC was performed on an Agilent 1100 Series HPLC System (Agilent, USA). Sample analysis for all HPLC experiments was achieved with an in-line diode array detector (DAD) and in-line fluorescence detector (FLD). Size exclusion chromatography (SEC) was performed using a Polysep-GFC-P-5000 column $(4.6 \times 250 \mathrm{~mm})($ Phenomenex, USA) at $1 \mathrm{~mL} / \mathrm{min}$ using a mobile phase of $10 \mathrm{mM}$ sodium phosphate buffer at $\mathrm{pH}$ 7.2. 


\section{Experimental Procedures}

Preparation of $5 \mathrm{~nm}$ BSPP-stabilized AuNPs. ${ }^{3}$ Bis( $p$-sulfonatophenyl)phenylphosphine (BSPP) was dissolved to $4 \mathrm{mg} / \mathrm{mL}$ in $\mathrm{ddH}_{2} \mathrm{O}$. To every $1 \mathrm{~mL}$ of citrate-stabilized $5 \mathrm{~nm}$ AuNPs was added $100 \mu \mathrm{L}$ of the BSPP solution. The solution was rotated end-over-end overnight at room temperature. The AuNPs were washed repeatedly with $1 \mathrm{mM}$ aqueous BSPP in $100 \mathrm{kDa}$ MWCO spin filters and concentrated 10-fold.

Preparation of phenol- or methoxy-AuNPs. A solution of concentrated $5 \mathrm{~nm}$ BSPP-stabilized AuNPs was diluted 10-fold with an aqueous solution of the phenol- or methoxy-PEG5k ligand (see synthetic procedures and general methods), such that the final concentration of ligand was $1 \mathrm{mg} / \mathrm{mL}$. The solution was rotated end-over-end overnight at room temperature. The AuNPs were washed with $\mathrm{ddH}_{2} \mathrm{O}$ in $100 \mathrm{kDa} \mathrm{MWCO}$ spin filters, concentrated 10 -fold, and stored at $4{ }^{\circ} \mathrm{C}$ until use.

DTNB capping of aldolase. 5,5'-dithio-bis-(2-nitrobenzoic acid) (DTNB, $2 \mathrm{mM}$ final concentration) was combined with aldolase $(100 \mu \mathrm{M})$ in $50 \mathrm{mM}$ phosphate buffer at $\mathrm{pH} 8$. The reaction was incubated at room temperature for $15 \mathrm{~min}$ (a bright yellow color was observed). The solution was spin concentrated with 10 kDa MWCO spin filters and $10 \mathrm{mM}$ phosphate buffer at $\mathrm{pH} 7.2$ (4 spins total at 14,500 xg).

Oxidative coupling to prepare protein-AuNP conjugates. Phenol- or methoxy-AuNPs (400 nM final concentration, $\epsilon=9.3 \times 10^{6} \mathrm{M}^{-1} \mathrm{~cm}^{-1}$ ) were combined with sfGFP-S200C, DTNB-capped aldolase, or prosfGFP ( $5 \mu \mathrm{M}$ final concentration) and abTyr (200 nM final concentration) in $20 \mathrm{mM}$ phosphate buffer at $\mathrm{pH}$ 6.5. The reaction was rotated end-over-end at room temperature for $2 \mathrm{~h}$ and then quenched with aniline and tropolone ( $5 \mathrm{mM}$ and $1 \mathrm{mM}$ final concentrations, respectively). Samples with sfGFP were spin concentrated with $100 \mathrm{kDa}$ MWCO spin filters and $\mathrm{ddH}_{2} \mathrm{O}$ (two spins total at 7,000 xg). For native agarose gel electrophoresis, gels were run for $60 \mathrm{~min}$.

Immobilized aldolase activity assay. Phenol- or methoxy-AuNPs (400 nM final concentration, $\epsilon=9.3 \times 10^{6}$ $\mathrm{M}^{-1} \mathrm{~cm}^{-1}$ ) were combined with DTNB-capped aldolase (500 nM final concentration) and abTyr (200 nM final concentration) in $20 \mathrm{mM}$ phosphate buffer at $\mathrm{pH}$ 6.5. The reactions were rotated end-over-end at room temperature for $2 \mathrm{~h}$ and then quenched with aniline and tropolone $(5 \mathrm{mM}$ and $1 \mathrm{mM}$ final concentrations, respectively). The activity of immobilized aldolase versus soluble aldolase was based on a protocol previously published. ${ }^{4}$ Briefly, aldolase-AuNPs (positive condition with phenol-AuNPs, DTNB-capped aldolase, and abTyr), phenol-AuNPs + DTNB-capped aldolase (negative control with no abTyr), methoxyAuNPs + DTNB-capped aldolase + abTyr (negative control with no phenols), phenol-AuNPs + abTyr (negative control with no DTNB-capped aldolase), and methoxy-AuNPs (negative control with no phenols, DTNB-capped aldolase, or abTyr) were diluted ( $20 \mathrm{nM}$ final concentration of aldolase for a $200 \mu \mathrm{L}$ final volume $)$ in assay buffer $(20 \mathrm{mM}$ phosphate buffer at $\mathrm{pH} 8.5)$. To this solution was added $\mathrm{NAD}^{+}(1 \mathrm{mM}$ final concentration for a $200 \mu \mathrm{L}$ final volume) and GAPDH $(1.35 \mu \mathrm{M}$ final concentration for a $200 \mu \mathrm{L}$ final volume). Just before absorbance measurements, FBP was added to a final concentration of $100 \mu \mathrm{M}$, bringing the total volume of each sample to $200 \mu \mathrm{L}$ in a 96-well plate. Immediately after adding FBP, the absorbance at $340 \mathrm{~nm}$ was measured every $2 \mathrm{~min}$ for $5 \mathrm{~h}$ at $37^{\circ} \mathrm{C}$ in a Tecan microplate reader. All samples were run in triplicate.

Preparation of streptavidin-biotin-AuNPs. Phenol- or methoxy-AuNPs (400 nM final concentration, $\epsilon=$ $\left.9.3 \times 10^{6} \mathrm{M}^{-1} \mathrm{~cm}^{-1}\right)$ were combined with biotin-PEG4-aniline (10 $\mu \mathrm{M}$ final concentration), and abTyr (200 $\mathrm{nM}$ final concentration) in $20 \mathrm{mM}$ phosphate buffer at $\mathrm{pH}$ 6.5. The reaction was rotated end-over-end at room temperature for $2 \mathrm{~h}$ and then quenched with aniline and tropolone $(5 \mathrm{mM}$ and $1 \mathrm{mM}$ final concentrations, respectively). Samples were spin concentrated with $100 \mathrm{kDa}$ MWCO spin filters and ddH $\mathrm{H}_{2} \mathrm{O}$ (two spins total at $14,500 \mathrm{xg}$ ). Streptavidin $(5 \mu \mathrm{M}$ final concentration) was added, and the mixture was shaken at $37^{\circ} \mathrm{C}$ for $1 \mathrm{~h}$ and then incubated at $4{ }^{\circ} \mathrm{C}$ overnight. 
Reduction of thiol-DNA for conjugation to AuNPs. Thiol-DNA of the following sequence was used for all primary conjugation of DNA to AuNPs: [ThiC6]CCCTAGAGTGAGTCGTATGA.

Before use, the DNA was reduced in $\mathrm{ddH}_{2} \mathrm{O}$ with TCEP $(2 \mathrm{eq})$ for $2.5 \mathrm{~h}$ at room temperature. The reduced DNA was purified with a NAP-5 column and then lyophilized overnight.

Oxidative coupling to prepare DNA-AuNP conjugates. Phenol- or methoxy-AuNPs (400 $\mathrm{nM}$ final concentration, $\left.\epsilon=9.3 \times 10^{6} \mathrm{M}^{-1} \mathrm{~cm}^{-1}\right)$ were combined with reduced thiol-DNA $(4,20,40,60$, or $80 \mu \mathrm{M}$ final concentration), and abTyr (200 $\mathrm{nM}$ final concentration) in $20 \mathrm{mM}$ phosphate buffer at $\mathrm{pH} 6.5$. The reaction was rotated end-over-end at room temperature for $2 \mathrm{~h}$ and then quenched with aniline and tropolone $(5 \mathrm{mM}$ and $1 \mathrm{mM}$ final concentrations, respectively). For native agarose gel electrophoresis, gels were run for 90 min. For DLS analysis, samples were first spin concentrated with $100 \mathrm{kDa}$ MWCO spin filters and $\mathrm{ddH}_{2} \mathrm{O}$ (two spins total at 14,500 $\mathrm{xg}$ ). For experiments with $40 \mathrm{nM}$ AuNPs, final thiol-DNA concentrations were $0.4,2$, or $8 \mu \mathrm{M}$. These lower concentration experiments were concentrated with $100 \mathrm{kDa}$ MWCO spin filters prior to analysis. For samples (both $40 \mathrm{nM}$ and $400 \mathrm{nM}$ ) prepared for DNA quantification: After quenching, $\mathrm{NaCl}$ was added to a final concentration of $300 \mathrm{mM}$ and samples were rotated end-over-end at room temperature for $30 \mathrm{~min}$ (to minimize background adsorption of DNA). Samples were then spin concentrated with $100 \mathrm{kDa}$ MWCO spin filters and $\mathrm{ddH}_{2} \mathrm{O}$ x1, $5 \mathrm{mM}$ HEPES at $\mathrm{pH} 7.7$ with $150 \mathrm{mM} \mathrm{NaCl}$ $\mathrm{x} 2$, and $\mathrm{ddH}_{2} \mathrm{O} \times 1$ (all at $14,500 \mathrm{xg}$ ).

DNA hybridization. DNA of the following palindromic complementary sequence was used for hybridization to DNA-AuNPs: GGGATCTCACTCAGCATACTTCATACGACTCACTCTAGGG

The above complementary DNA sequence was added to DNA-AuNPs at 10x the concentration of thiolDNA used for preparation of the DNA-AuNPs (e.g. $200 \mu \mathrm{M}$ of the complementary stand was used for DNA-AuNPs that were prepared with $20 \mu \mathrm{M}$ thiol-DNA). The samples were heated to $70{ }^{\circ} \mathrm{C}$ for 10 min and then allowed to stand at room temperature overnight before analysis by DLS.

DNA quantification. After preparing samples as described above, $\mathrm{KCN}$ (35 $\mathrm{mM}$ final concentration in $\mathrm{ddH}_{2} \mathrm{O}$ ) was added to an aliquot of each sample and rotated end-over-end overnight at room temperature to dissolve the AuNPs. DNA released into solution was quantified with an OliGreen ssDNA Assay Kit (carried out in a 96-well plate format with triplicate measurements). The following DNA sequence was used to prepare the standard curve: CCCTAGAGTGAGTCGTATGA. To obtain the DNA per AuNP ratio, the concentration of DNA determined by the quantification kit was divided by the concentration (as determined by UV-vis) of the corresponding purified DNA-AuNP samples.

Oxidative coupling to prepare cpTMV-AuNP conjugates. Phenol- or methoxy-AuNPs (400 nM final concentration, $\epsilon=9.3 \times 10^{6} \mathrm{M}^{-1} \mathrm{~cm}^{-1}$ ) were combined with cpTMV-S23C-S65pAF, cpTMV, or cpTMVS23C-S65pAF-OG488 $(0.1,0.2,0.3,0.4$, or $0.5 \mu \mathrm{M}$ final capsid concentration), and abTyr (200 nM final concentration) in $20 \mathrm{mM}$ phosphate buffer at $\mathrm{pH}$ 6.5. The reaction proceeded end-over-end at room temperature for $2 \mathrm{~h}$ and then was quenched with aniline and tropolone $(5 \mathrm{mM}$ and $1 \mathrm{mM}$ final concentrations, respectively). For native agarose gel electrophoresis, gels were run for $60 \mathrm{~min}$. cpTMVAuNP conjugates were not purified prior to analysis by gel electrophoresis, DLS, or TEM.

Preparation of cpTMV-S23C-S65pAF-OG488 and cpTMV-S65pAF-Q101C-OG488. cpTMV-S23C$\mathrm{S} 65 \mathrm{pAF}(25 \mu \mathrm{M}$ monomer) was combined with Oregon Green 488 maleimide $(250 \mu \mathrm{M}, 10 \mathrm{eq})$ in $40 \mathrm{mM}$ phosphate buffer at $\mathrm{pH} 7$. The reaction proceeded at $4{ }^{\circ} \mathrm{C}$ overnight. Excess dye was removed through spin concentration with $10 \mathrm{kDa}$ MWCO spin filters. Successful conjugation was confirmed with ESI-TOF LCMS. This procedure was repeated with cpTMV-S65pAF-Q101C.

Preparation of cpTMV-AuNP conjugates for TEM. cpTMV-AuNP conjugates for TEM analysis were generated with $1.5 \mu \mathrm{M}$ phenol- or methoxy-AuNPs and $0.75 \mu \mathrm{M}$ cpTMV-S65pAF or cpTMV. All other conditions were the same as previously described. 


\title{
Expression and Purification of cpTMV Mutants
}

\author{
Construction of cpTMV expression plasmids
}

pDule-para-aminoPhe (Addgene \#85502) ${ }^{5}$ and pBad-sfGFP 150TAG (Addgene \#85483) ${ }^{6}$ plasmids were gifts from Ryan Mehl.

The gene of the circular permutant of TMV (cpTMV) was produced using standard molecular biology techniques based on a gene for the coat protein of the TMV U1 strain optimized for the codon usage of $E$. coli (Genscript, Piscataway, $\mathrm{NJ}$ ) as reported by Dedeo et al. ${ }^{7}$ The $\mathrm{S} 23 \mathrm{C}$ and Q101C mutations were made as previously reported. ${ }^{8}$ The cpTMV gene was inserted into a $\mathrm{pBad} / \mathrm{myc}$-His A vector (pBad-sfGFP 150TAG) using a Gibson Assembly kit (New England Biotechnology, Ipswich, MA). Site-directed mutagenesis was performed using a PfuUltra II Fusion HS DNA Polymerase kit (Agilent, Santa Clara, CA). The following sets of primers were used for these mutations, where * represents the amber codon TAG:

Excision of $\mathrm{pBad} / \mathrm{myc}-\mathrm{His}$ A entry vector from $\mathrm{pBad}-\mathrm{sfGFP}$ 150TAG:

Sense: 5' TAAAGCTCGAGATCTGCAGCT 3'

Antisense: 5' CATGGTTAATTCCTCCTGTTAGC 3'

Insertion of cpTMV into $\mathrm{pBad} / \mathrm{myc}-\mathrm{His} \mathrm{A}$ entry vector:

Sense: 5' GCTAACAGGAGGAATTAACCATGGGCGCCAATCCGACCA 3'

Antisense: 5' AGCTGCAGATCTCGAGCTTTACTGGTTTTCCACTTCAATGATAC 3'

S65*:

Sense: 5' GGGCGAAGGCAGCTATTAGATTACCACCCCGAGCC 3' Antisense: 5' GGGGTGGTAATCTAATAGCTGCCTTCGCCCGCC 3'

\section{Protein expression and purification}

The following conditions and general procedure for the production of $p$-amino-L-phenylalanine ( $p$ AF)containing proteins are adapted from a previously published protocol ${ }^{9}$ with minimal modifications. The pBAD-cpTMV-S65*, pBAD-cpTMV-S23C-S65* or pBAD-cpTMV-S65*-Q101C vectors with pDulepAF were co-transformed into DH10B E. coli cells and plated on LB agar plates containing $50 \mu \mathrm{g} / \mathrm{mL}$ ampicillin and $12.5 \mu \mathrm{g} / \mathrm{mL}$ tetracycline. The resulting colonies were grown overnight in $10 \mathrm{~mL}$ of LB containing $50 \mu \mathrm{g} / \mathrm{mL}$ ampicillin and $12.5 \mu \mathrm{g} / \mathrm{mL}$ tetracycline at $37^{\circ} \mathrm{C}$ and then added to $1 \mathrm{~L}$ of arabinose media (recipe below). The $1 \mathrm{~L}$ culture was allowed to shake at $37^{\circ} \mathrm{C}, 220 \mathrm{rpm}$, until it reached an $\mathrm{OD}_{600}$ of $0.6-0.8$. Then, $10 \mathrm{~mL}$ of a $100 \mathrm{mM}$ solution of $p \mathrm{AF}$ in $\mathrm{ddH}_{2} \mathrm{O}$ was added to the growth medium to a final concentration of $1 \mathrm{mM}$ (instructions for preparation of this solution are below). The culture was incubated at $37^{\circ} \mathrm{C}, 220 \mathrm{rpm}$, for an additional $18 \mathrm{~h}$. Cell pellets were collected at 8,000 rpm for $30 \mathrm{~min}$, after which the supernatant was discarded, and the cell pellets were frozen at $-20{ }^{\circ} \mathrm{C}$ until purification.

The purification of cpTMV proteins is based on a previously reported procedure ${ }^{9}$ with minimal modifications. After freezing, cell pellets were partially thawed and resuspended in $10 \mathrm{~mL}$ lysis buffer with $20 \mathrm{mM}$ triethanolamine (TEA) at $\mathrm{pH}$ 7.2. Cells were lysed by sonication with a $2 \mathrm{~s}$ on, $4 \mathrm{~s}$ off cycle for a total of 10 min using a standard disruptor horn at 60\% amplitude (Branson Ultrasonics, Danbury, CT). The resulting lysate was cleared at $14,000 \mathrm{rpm}$ for $30 \mathrm{~min}$. The supernatant was treated with 30 to $40 \%$ volume ( 3 to $4 \mathrm{~mL}$ ) of saturated ammonium sulfate and rotated for $10 \mathrm{~min}$ at $4{ }^{\circ} \mathrm{C}$ to allow for complete protein precipitation. The precipitated protein was collected at $11,000 \mathrm{rpm}$ for $30 \mathrm{~min}$ and resuspended in $10 \mathrm{~mL}$ of lysis buffer. Complete dissolution of the protein and removal of the residual ammonium sulfate was accomplished by performing dialysis in $1 \mathrm{~L}$ of lysis buffer overnight with at least one buffer exchange. The resulting protein solution was treated with $5 \mu \mathrm{L}$ benzonase nuclease (Millipore, Madison, WI) and $4 \mathrm{mg}$ 
$\mathrm{MgCl}_{2}$ at room temperature for $30 \mathrm{~min}$ before the solution was centrifuged at $10,000 \mathrm{rpm}$ for $10 \mathrm{~min}$. The resulting supernatant was filtered through a $0.22 \mu \mathrm{m}$ filter and purified using a diethylaminoethanol (DEAE) Sepharose column with a 0 to $300 \mathrm{mM} \mathrm{NaCl}$ gradient elution in $20 \mathrm{mM}$ TEA buffer at $\mathrm{pH}$ 7.2. The fractions containing cpTMV were further purified using a Sephacryl S-500 column in $10 \mathrm{mM}$ sodium phosphate at $\mathrm{pH} 7.2$ elution buffer. Pure fractions were collected and concentrated using Amicon Ultra 100 kDa MWCO centrifugal concentrators. Purity was confirmed by SDS-PAGE and ESI-TOF LC-MS (Figure S12). The assembly state was confirmed by HPLC-SEC, DLS, and TEM (Figure S13). The assembly state was compared to a protein of known structure, cpTMV-S23C. ${ }^{7}$ Protein was flash frozen and stored indefinitely at $-80{ }^{\circ} \mathrm{C}$ or stored for no longer than 2 weeks at $4{ }^{\circ} \mathrm{C}$ without observed decomposition or change in assembly state.

Arabinose media $\left(1 \mathrm{~L}, \mathrm{H}_{2} \mathrm{O}\right)$

$40 \mathrm{~mL} 25 \mathrm{x}$ M salts (1.25 $\mathrm{M} \mathrm{Na}_{2} \mathrm{HPO}_{4}, 1.25 \mathrm{M} \mathrm{KH}_{2} \mathrm{PO}_{4}, 2.5 \mathrm{M} \mathrm{NH} 4 \mathrm{Cl}, 0.25 \mathrm{M} \mathrm{Na}_{2} \mathrm{SO}_{4}$; autoclaved)

$2 \mathrm{~mL}_{1} \mathrm{M} \mathrm{MgSO}_{4}$ (autoclaved)

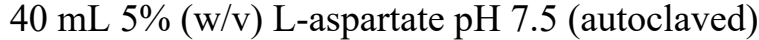

$20 \mathrm{ml} 4 \mathrm{mg} / \mathrm{mL}$ L-leucine $\mathrm{pH} 7.5$ (autoclaved)

$2.4 \mathrm{~mL} \mathrm{20 \%} \mathrm{glucose} \mathrm{(autoclaved)}$

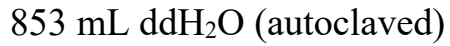

$40 \mathrm{~mL} 18$ amino acid solution at pH $7(5 \mathrm{mg} / \mathrm{mL}$ of every natural L-amino acid, excluding tyrosine and cysteine; sterile filtered)

$1 \mathrm{~mL} 1,000 \mathrm{x}$ heavy metal stock solution (sterile filtered)

$1.25 \mathrm{~mL} 20 \%$ arabinose (sterile filtered)

$12.5 \mathrm{mg}$ tetracycline

$50 \mathrm{mg}$ ampicillin

1,000x heavy metal stock solution $(1 \mathrm{~L}, 1 \mathrm{M} \mathrm{HCl})$

$500 \mathrm{mg} \mathrm{MoNa}_{2} \mathrm{O}_{2} \cdot 2 \mathrm{H}_{2} \mathrm{O}$

$250 \mathrm{mg} \mathrm{CoCl} 2$

$175 \mathrm{mg} \mathrm{CuSO}_{4} \cdot 5 \mathrm{H}_{2} \mathrm{O}$

$1 \mathrm{~g} \mathrm{MnSO}_{4} \cdot \mathrm{H}_{2} \mathrm{O}$

$8.75 \mathrm{~g} \mathrm{MgSO}_{4} \cdot 7 \mathrm{H}_{2} \mathrm{O}$

$1.25 \mathrm{~g} \mathrm{ZnSO}_{4} \cdot 7 \mathrm{H}_{2} \mathrm{O}$

$1.25 \mathrm{~g} \mathrm{FeCl}_{2} \cdot 4 \mathrm{H}_{2} \mathrm{O}$

$2.5 \mathrm{~g} \mathrm{CaCl}_{2} \cdot 2 \mathrm{H}_{2} \mathrm{O}$

$1 \mathrm{~g} \mathrm{H}_{3} \mathrm{BO}_{3}$

Solutions containing noncanonical amino acids were prepared no more than $1 \mathrm{~h}$ prior to addition to cell

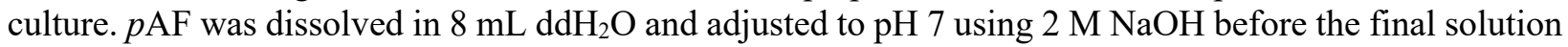
volume was brought to $10 \mathrm{~mL}$ using $\mathrm{ddH}_{2} \mathrm{O}$. The solution was then stored at $4{ }^{\circ} \mathrm{C}$ until use.

\begin{tabular}{|l|l|l|}
\hline \multicolumn{3}{|l|}{ DLS-determined particle diameters of cpTMV mutants } \\
\hline Sample name & Intensity mean $(\mathrm{nm})$ & PdI mean \\
\hline cpTMV-S23C & $20.7 \pm 0.3$ & $0.17 \pm 0.02$ \\
\hline cpTMV-S65pAF & $19.0 \pm 0.4$ & $0.12 \pm 0.01$ \\
\hline cpTMV-S23C-S65pAF & $20.4 \pm 0.3$ & $0.15 \pm 0.01$ \\
\hline cpTMV-S65pAF-Q101C & $20.3 \pm 0.3$ & $0.22 \pm 0.01$ \\
\hline
\end{tabular}




\section{Synthetic Procedures}

Synthesis of lipoic acid-NHS (based on a previously reported procedure $\left.{ }^{10}\right)$. Lipoic acid (406 mg, $1 \mathrm{eq}$ ) and $\mathrm{N}$-hydroxysuccinimide (NHS) (230 mg, $1 \mathrm{eq}$ ) were dissolved in $4 \mathrm{~mL}$ of dry DCM. Separately, $N, N^{\prime}-$ dicyclohexylcarbodiimide (DCC) (413 mg, $0.94 \mathrm{eq}$ ) was dissolved in $3 \mathrm{~mL}$ of dry DCM. The lipoic acid solution was added dropwise to the DCC solution, and the mixture was stirred on ice for $1 \mathrm{~h}$. The reaction was then stirred at $4{ }^{\circ} \mathrm{C}$ for $1 \mathrm{~h}$, after which the stirring was stopped, and the mixture was left overnight at $4{ }^{\circ} \mathrm{C}$. The next morning, the mixture was placed in a $-20{ }^{\circ} \mathrm{C}$ freezer for $30 \mathrm{~min}$. The solution was then filtered with a Buchner funnel, and the collected solid was washed with two $3 \mathrm{~mL}$ portions of DCM that were pre-cooled to $-20^{\circ} \mathrm{C}$. The filtrate was collected and subjected to rotary evaporation. The resulting pale-yellow solid was confirmed by ${ }^{1} \mathrm{H}$ NMR in $\mathrm{CDCl}_{3}$ (Figure $\mathrm{S} 14$ ).

Synthesis of lipoamide-PEG5k-valeric acid (based on a previously reported procedure ${ }^{10}$ ). Amine-PEG5kvaleric acid (100 mg, $1 \mathrm{eq}$ ) and lipoic acid-NHS (30 mg, 5 eq) were dissolved in $0.5 \mathrm{~mL}$ of dry DCM in a $4 \mathrm{~mL}$ vial. Triethylamine $(27 \mu \mathrm{L}, 10 \mathrm{eq})$ was added, and the reaction was stirred overnight at room temperature. The next morning, the reaction was concentrated under a gentle stream of nitrogen, and then $1 \mathrm{~mL}$ of $\mathrm{ddH}_{2} \mathrm{O}$ was added. The mixture was filtered through a $0.22 \mu \mathrm{m}$ cellulose-acetate spin filter. To remove small molecules, the filtrate was repeatedly spin concentrated with $\mathrm{ddH}_{2} \mathrm{O}$ in a $3 \mathrm{kDa} \mathrm{MWCO}$ spin filter. The resulting product was lyophilized to afford a white solid product.

Synthesis of thiol-PEG5k-phenol. Lipoamide-PEG5k-valeric acid (30 mg, $1 \mathrm{eq})$, DCC (12.3 mg, $10 \mathrm{eq})$, and NHS (6.9 mg, 10 eq) were dissolved in $1 \mathrm{~mL}$ of dry DCM in a $4 \mathrm{~mL}$ vial and stirred for $1 \mathrm{~h}$ at room temperature. Tyramine $(8.25 \mathrm{mg}, 10 \mathrm{eq})$ was added, and the reaction was stirred overnight at room temperature. The next morning, the reaction was concentrated under a gentle stream of nitrogen, and then $1 \mathrm{~mL}$ of $\mathrm{ddH}_{2} \mathrm{O}$ was added. The mixture was filtered through a $0.22 \mu \mathrm{m}$ cellulose-acetate spin filter. To remove small molecules, the filtrate was repeatedly spin concentrated with $\mathrm{ddH}_{2} \mathrm{O}$ in a $3 \mathrm{kDa} \mathrm{MWCO}$ spin filter. The resulting product was lyophilized to afford a white solid product that was confirmed by ${ }^{1} \mathrm{H} N \mathrm{NR}$ in $\mathrm{CDCl}_{3}$ (Figure S15).

Synthesis of biotin-PEG4-aniline. EZ-Link NHS-PEG4-biotin (44 mM, $1.1 \mathrm{eq})$ was combined with 4-(2aminoethyl)aniline (1 eq) in DMF. The mixture was rotated end-over-end overnight at room temperature. Formation of the product was confirmed with LC-MS. The solution was diluted to a concentration of 4.5 $\mathrm{mM}$ prior to use. QTOF-MS: $m / z$ for $\mathrm{C}_{28} \mathrm{H}_{47} \mathrm{~N}_{5} \mathrm{O}_{7} \mathrm{~S}[\mathrm{M}+\mathrm{H}]^{+} 610.3$, observed 610.3. 


\section{References}

(1) Obermeyer, A. C.; Jarman, J. B.; Netirojjanakul, C.; El Muslemany, K.; Francis, M. B. Mild Bioconjugation Through the Oxidative Coupling of Ortho-Aminophenols and Anilines with Ferricyanide. Angew. Chem. Int. Ed. 2014, 53 (4), 1057-1061.

(2) Lobba, M. J.; Fellmann, C.; Marmelstein, A. M.; Maza, J. C.; Kissman, E. N.; Robinson, S. A.; Staahl, B. T.; Urnes, C.; Lew, R. J.; Mogilevsky, C. S.; Doudna, J. A.; Francis, M. B. Site-Specific Bioconjugation through Enzyme-Catalyzed Tyrosine-Cysteine Bond Formation. ACS Cent. Sci. 2020, 6 (9), 1564-1571.

(3) Liu, A.; Verwegen, M.; de Ruiter, M. V.; Maassen, S. J.; Traulsen, C. H.-H.; Cornelissen, J. J. L. M. Protein Cages as Containers for Gold Nanoparticles. J. Phys. Chem. B 2016, 120 (26), 6352-6357.

(4) Palla, K. S.; Hurlburt, T. J.; Buyanin, A. M.; Somorjai, G. A.; Francis, M. B. Site-Selective Oxidative Coupling Reactions for the Attachment of Enzymes to Glass Surfaces through DNA-Directed Immobilization. J. Am. Chem. Soc. 2017, 139 (5), 1967-1974.

(5) Mehl, R. A.; Anderson, J. C.; Santoro, S. W.; Wang, L.; Martin, A. B.; King, D. S.; Horn, D. M.; Schultz, P. G. Generation of a Bacterium with a 21 Amino Acid Genetic Code. $J$. Am. Chem. Soc. 2003, 125, 935-939.

(6) Miyake-Stoner, S. J.; Refakis, C. A.; Hammill, J. T.; Lusic, H.; Hazen, J. L.; Deiters, A.; Mehl, R. A. Generating Permissive Site-Specific Unnatural Aminoacyl-tRNA Synthetases. Biochemistry 2010, 49, 1667-1677.

(7) Dedeo, M. T.; Duderstadt, K. E.; Berger, J. M.; Francis, M. B. Nanoscale Protein Assemblies from a Circular Permutant of the Tobacco Mosaic Virus. Nano Lett. 2010, 10 (1), 181-186.

(8) Delor, M.; Dai, J.; Roberts, T. D.; Rogers, J. R.; Hamed, S. M.; Neaton, J. B.; Geissler, P. L.; Francis, M.B.; Ginsberg, N. S. Exploiting Chromophore-Protein Interactions through Linker Engineering To Tune Photoinduced Dynamics in a Biomimetic Light-Harvesting Platform. J. Am. Chem. Soc. 2018, 140, 6278-6287.

(9) Hammill, J. T.; Miyake-Stoner, S.; Hazen, J. L.; Jackson, J. C.; Mehl, R. A. Preparation of Site-Specifically Labeled Fluorinated Proteins for ${ }^{19}$ F-NMR Structural Characterization. Nat. Protoc. 2007, 2, 2601-2607.

(10) Capehart, S. L.; ElSohly, A. M.; Obermeyer, A. C.; Francis, M. B. Bioconjugation of Gold Nanoparticles through the Oxidative Coupling of Ortho-Aminophenols and Anilines. Bioconjugate Chem. 2014, 25 (10), 1888-1892. 
A
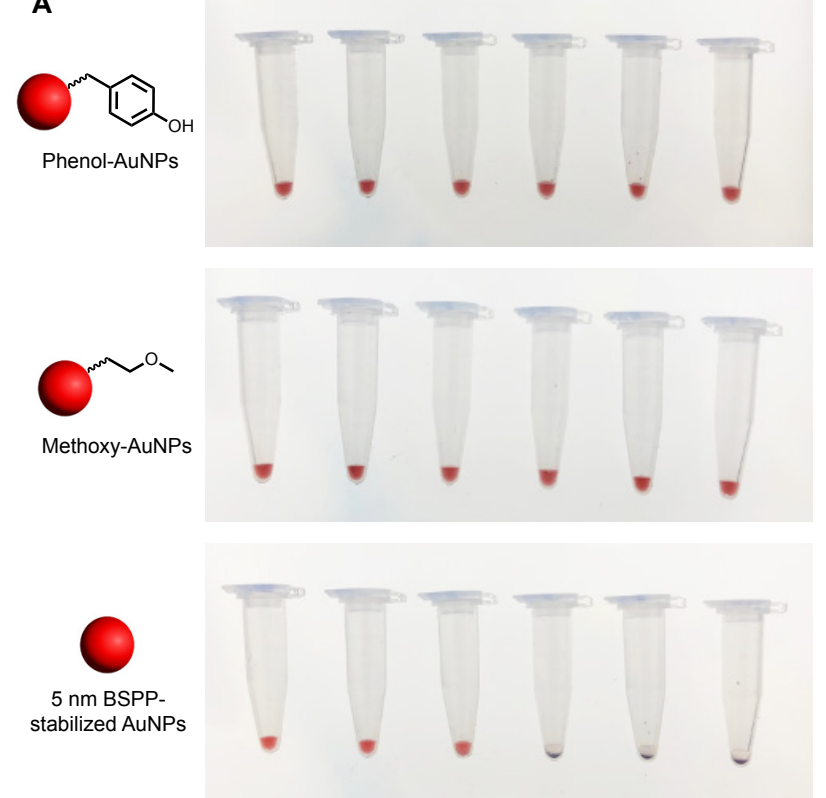

0

0.1

0.2

$0.5 \quad 0.8$

1

$\mathrm{NaCl}$ Concentration (M)

B

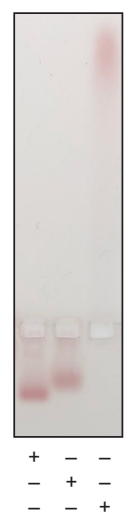

Figure S1. Characterization of phenol- and methoxy-AuNPs via a salt stability screen and electrophoresis. (A) Overnight incubation of AuNPs with various salt concentrations demonstrated that both methoxy and phenol monolayers prevented AuNPs from aggregating in the presence of high salt concentrations. In contrast, AuNPs that were stabilized only with BSPP aggregated as salt concentrations approached $0.5 \mathrm{M}$. (B) Native agarose gel elecetrophoresis demonstrated significant changes in electrophoretic mobility upon monolayer formation. 

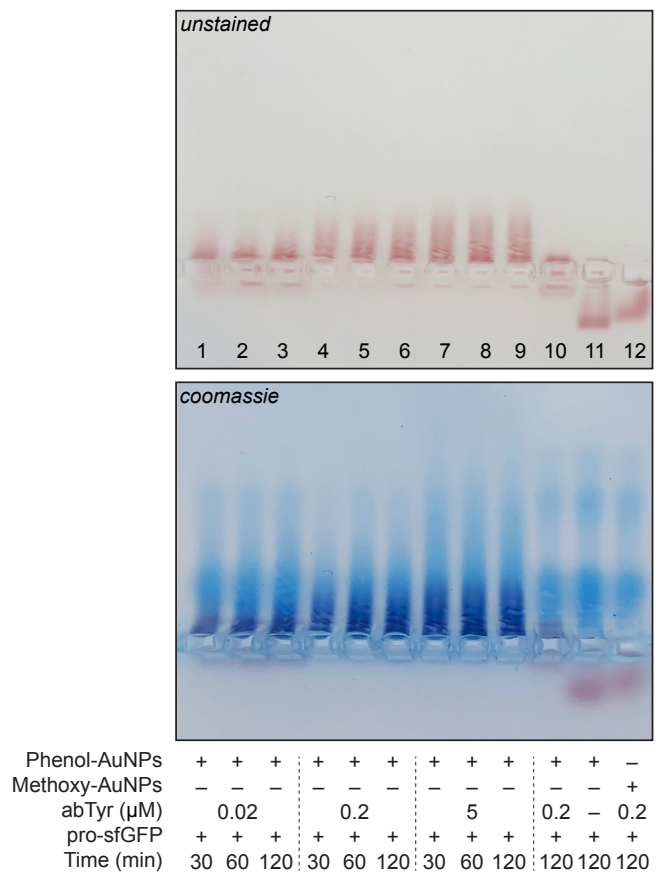

Figure S2. Screen of oxidative coupling reaction times and tyrosinase concentrations. Oxidative coupling reactions were used to conjugate pro-sfGFP to phenol-AuNPs with different reaction times and concentrations of tyrosinase (abTyr). Reactions were run with $5 \mu \mathrm{M}$ pro-sfGFP and $400 \mathrm{nM}$ phenol- or methoxy-AuNPs and were quenched with $5 \mathrm{mM}$ aniline and $1 \mathrm{mM}$ troplone. The sample in lane 10 was a negative control in which aniline was added at the same time as pro-sfGFP. As expected, the aniline reacted faster than pro-sfGFP, and no protein coupling was observed. The shift in AuNP mobility for this sample was due to oxidation of the surface phenols. 


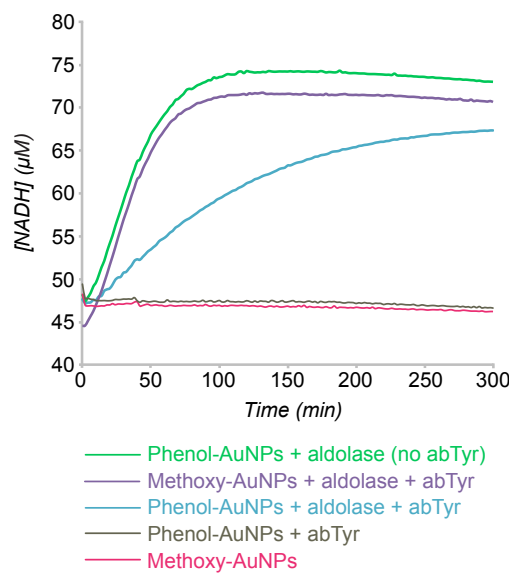

Figure S3. Activity assay of immobilized aldolase. Immobilized aldolase (blue) displayed reduced activity as compared to aldolase in solution with phenol-AuNPs but no tyrosinase (abTyr) (green) and aldolase in solution with methoxy-AuNPs and abTyr (purple). Reduced activity is likely due to active site obstruction from immobilization rather than mis-folding. Oxidative coupling reactions were carried out with $400 \mathrm{nM}$ AuNPs, $500 \mathrm{nM}$ aldolase, and $200 \mathrm{nM}$ abTyr. 
A

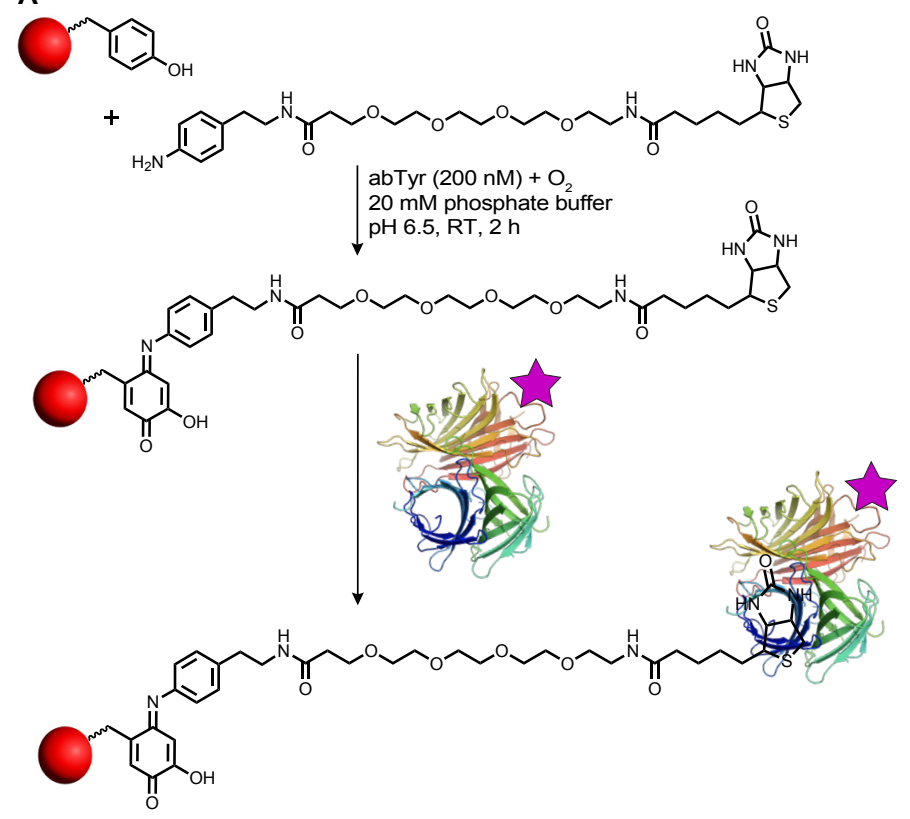

B

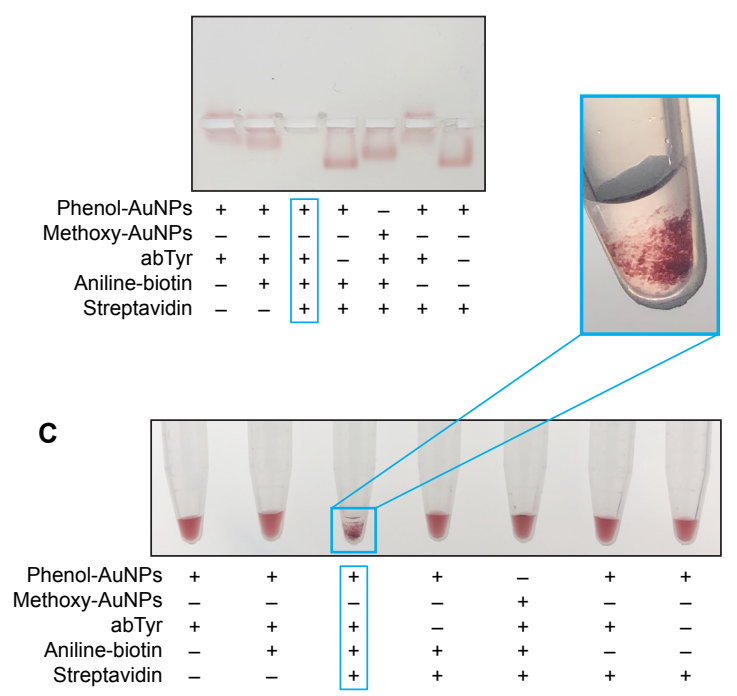

D

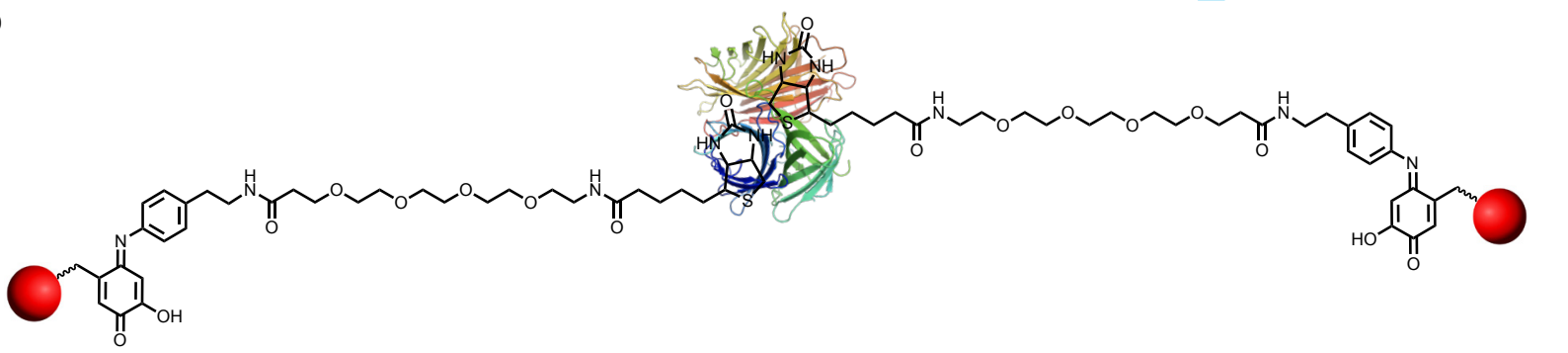

Figure S4. Coupling of aniline-biotin to phenol-AuNPs. (A) Aniline-biotin was synthesized and oxidatively coupled to phenol-AuNPs, followed by incubation with Texas red-labeled streptavidin to verify success of oxidative coupling. Reactions were carried out with $400 \mathrm{nM}$ AuNPs, $200 \mathrm{nM}$ tyosinase (abTyr), $10 \mu \mathrm{M}$ biotin, and $5 \mu \mathrm{M}$ streptavidin. (B) Agarose gel electrophoresis revealed quenching of Texas red when streptavidin was incubated with phenol-AuNPs that were exposed to abTyr during the biotin oxidative coupling reactions. This is likely from proximity-based quenching, present only when streptavidin is binding immobilized biotin. Lack of AuNP mobility is likely the result of large assembly formations, as discussed in part C. (C) After overnight incubation, large assemblies of AuNPs were observed only when both phenol-AuNPs and abTyr were present in the biotin oxidative coupling reactions, followed by streptavidin addition. (D) Large assembly formation is presumably due to streptavidin binding immobilized biotin on adjacent AuNPs. While this cartoon shows binding of only two AuNPs, a single streptavidin protein could bind up to four AuNPs. 


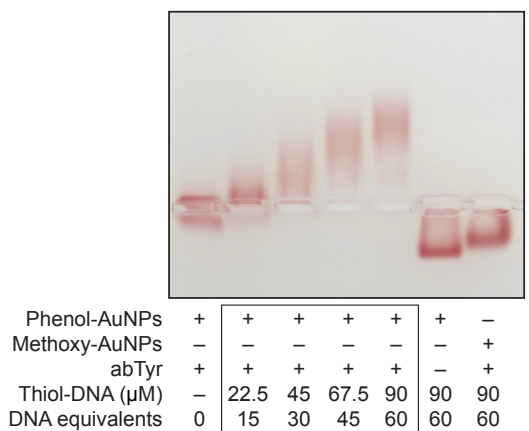

Figure S5. Concentration screen with lower concentrations of DNA. Thiol-DNA of various concentrations was reacted with phenol-AuNPs at $1.5 \mu \mathrm{M}$ in the presence of $200 \mathrm{nM}$ tyrosinase (abTyr). Despite shifts in mobility, DLS revealed no changes in size, likely due to conjugated DNA folding around the surface of AuNPs rather than being oriented radially. 

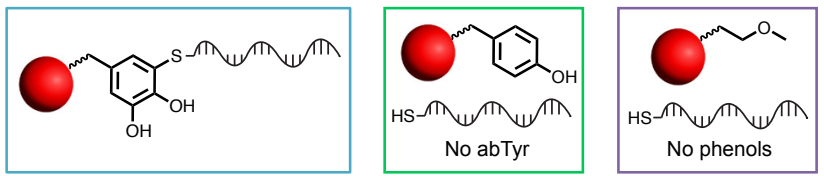

A
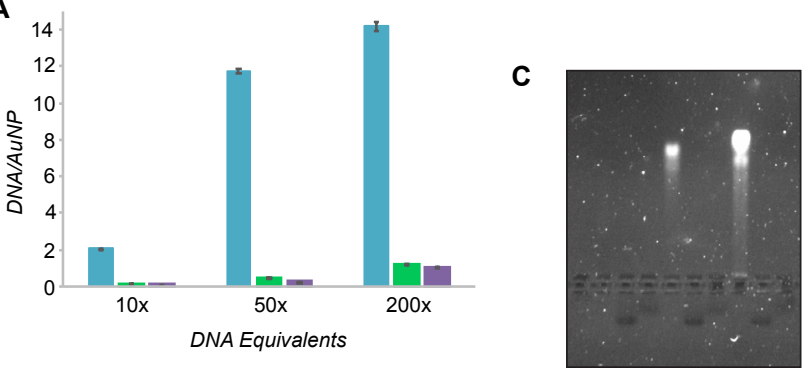

B
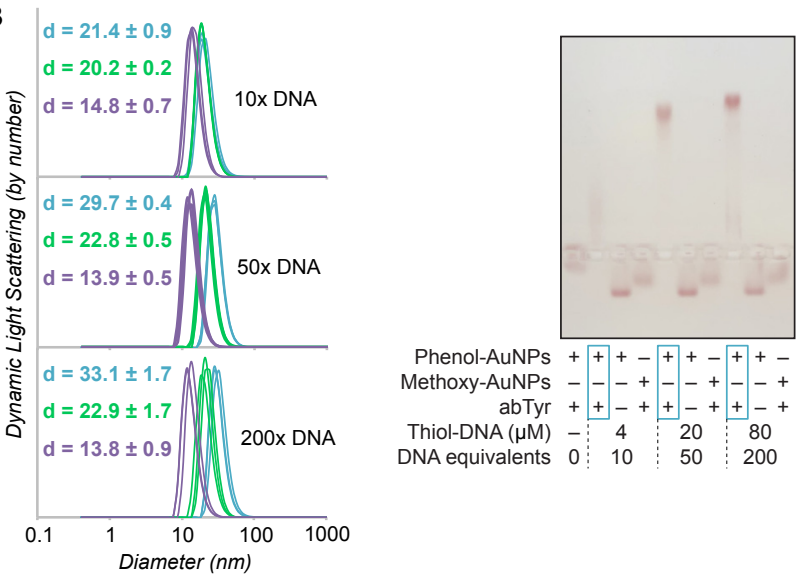

Figure S6. Quantification of DNA conjugated to phenol-AuNPs $(400 \mathrm{nM})$. (A) DNA quantification revealed that up to 14 strands of DNA can be oxidatively coupled to phenol-AuNPs in the presence of tyrosinase (abTyr) (blue) and that the number of conjugated DNA strands can be tuned by changing DNA concentration during oxidative coupling. Minimal background adsorption was observed in the absence of abTyr (green) and the absence of phenols (purple). All oxidative coupling reactions were carried out with $400 \mathrm{nM}$ AuNPs and $200 \mathrm{nM}$ abTyr. Error bars are from triplicate measurements of a single experiment. (B) The samples used for quantifying DNA per AuNP were also analyzed by DLS. The diameter of DNA-AuNPs increased as the number of DNA strands per AuNP increased. (C) Analysis by gel electrophoresis with an agarose gel containing SYBR Safe stain revealed fluorescent bands for DNA-AuNP samples with relatively high numbers of conjugated DNA strand. 

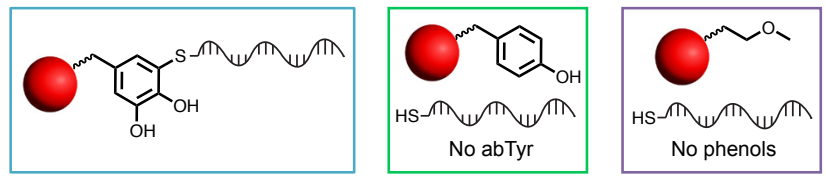

A

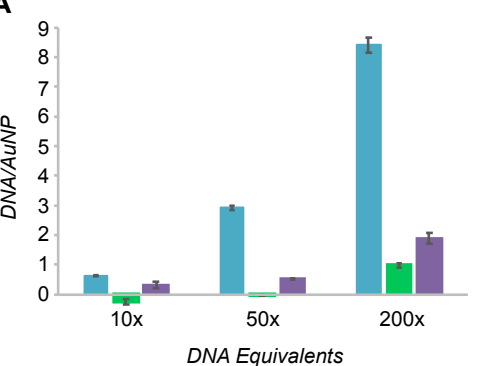

C
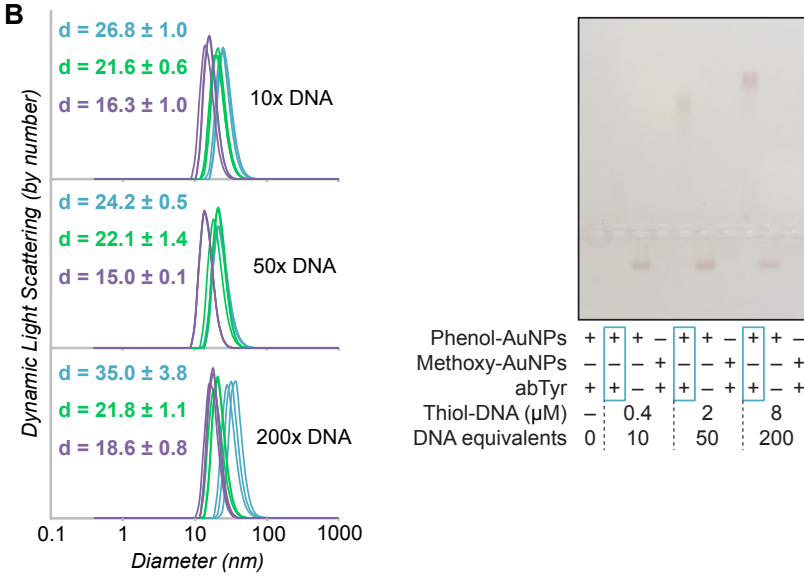

Figure S7. Quantification of DNA conjugated to phenol-AuNPs (40 $\mathrm{nM}$ ). (A) DNA quantification revealed that up to 8 strands of DNA can be oxidatively coupled to phenol-AuNPs in the presence of tyrosinase (abTyr) (blue) and that the number of conjugated DNA strands can be tuned by changing DNA concentration during oxidative coupling. Some background adsorption was observed in the absence of abTyr (green) and the absence of phenols (purple). All oxidative coupling reactions were carried out with $40 \mathrm{nM}$ AuNPs and $200 \mathrm{nM}$ abTyr. Error bars are from triplicate measurements of a single experiment. (B) The samples used for quantifying DNA strands per AuNP were also analyzed by DLS. While size increased upon conjugation to DNA (blue), variable measurements were produced, which is likely due to the low concentrations of AuNPs. (C) Mobility changes from analysis by gel electrophoresis confirmed conjugation, but analysis of the SYBR Safe stained gel under UV was inconclusive, presumably due to low AuNP concentrations. 
A

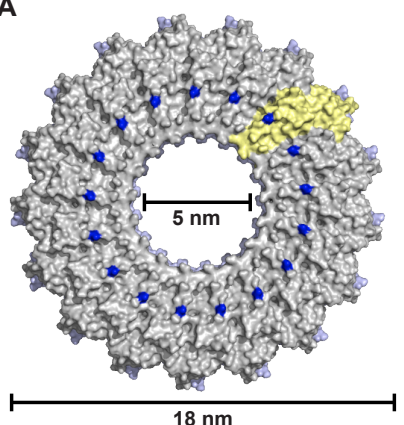

B
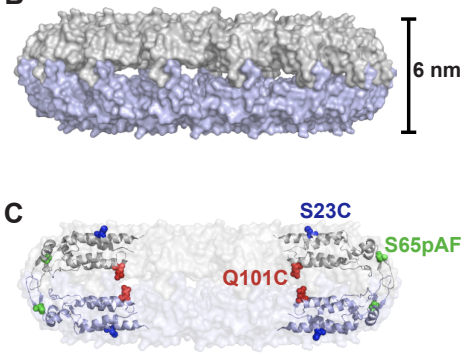

Figure S8. The double disk structure of cpTMV. cpTMV assembles into two disks, each comprising 17 monomers, and displays C2 symmetry. (A) The top-down view of cpTMV reveals the disk-like structure. A single monomer is shown in yellow. The surface S23C mutation site is highlighted in blue. (B) The side view of cpTMV shows the height of the double disk structure. (C) A cross-section of cpTMV highlights the mutation sites. The surface S23C mutation site is shown in blue, the inner cavity Q101C mutation site is shown in red, and the $\mathrm{S} 65 \mathrm{pAF}$ mutation site is shown in green. 
A Phenol-AuNPs + cpTMV-S65pAF (no abTyr)
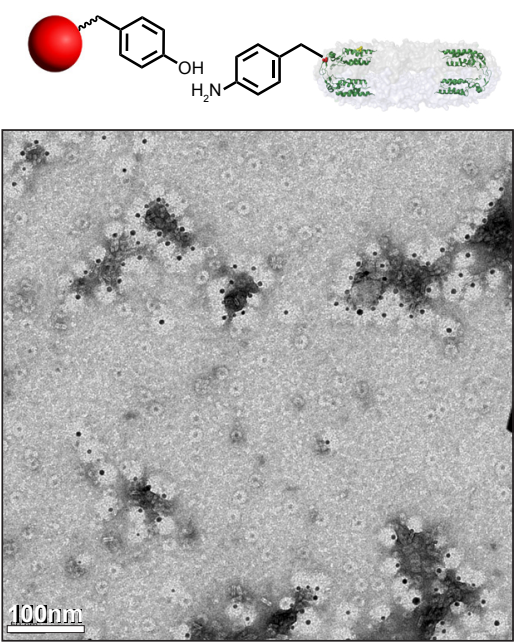

B Methoxy-AuNPs + cpTMV-S65pAF + abTyr (no phenols)
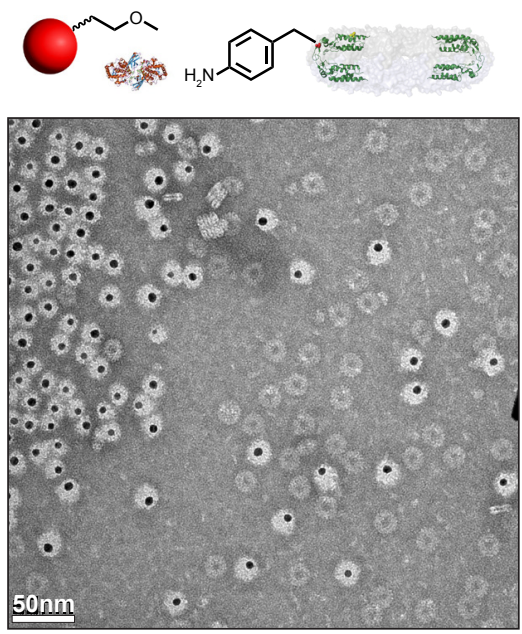

C Phenol-AuNPs + cpTMV + abTyr (no anilines)
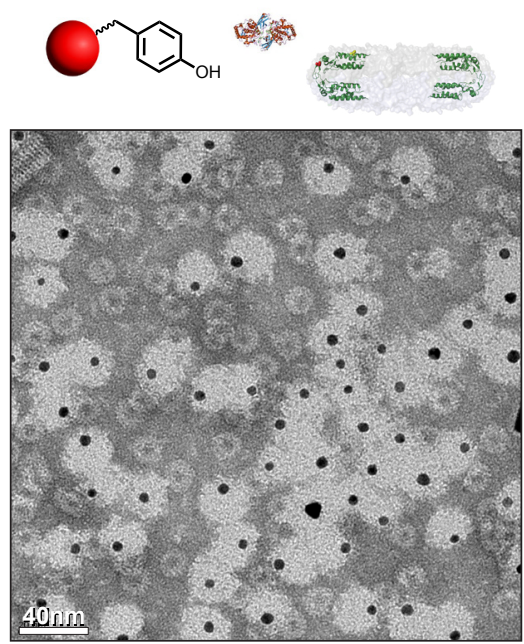

D

Phenol-AuNPs + cpTMV-S65pAF + abTyr
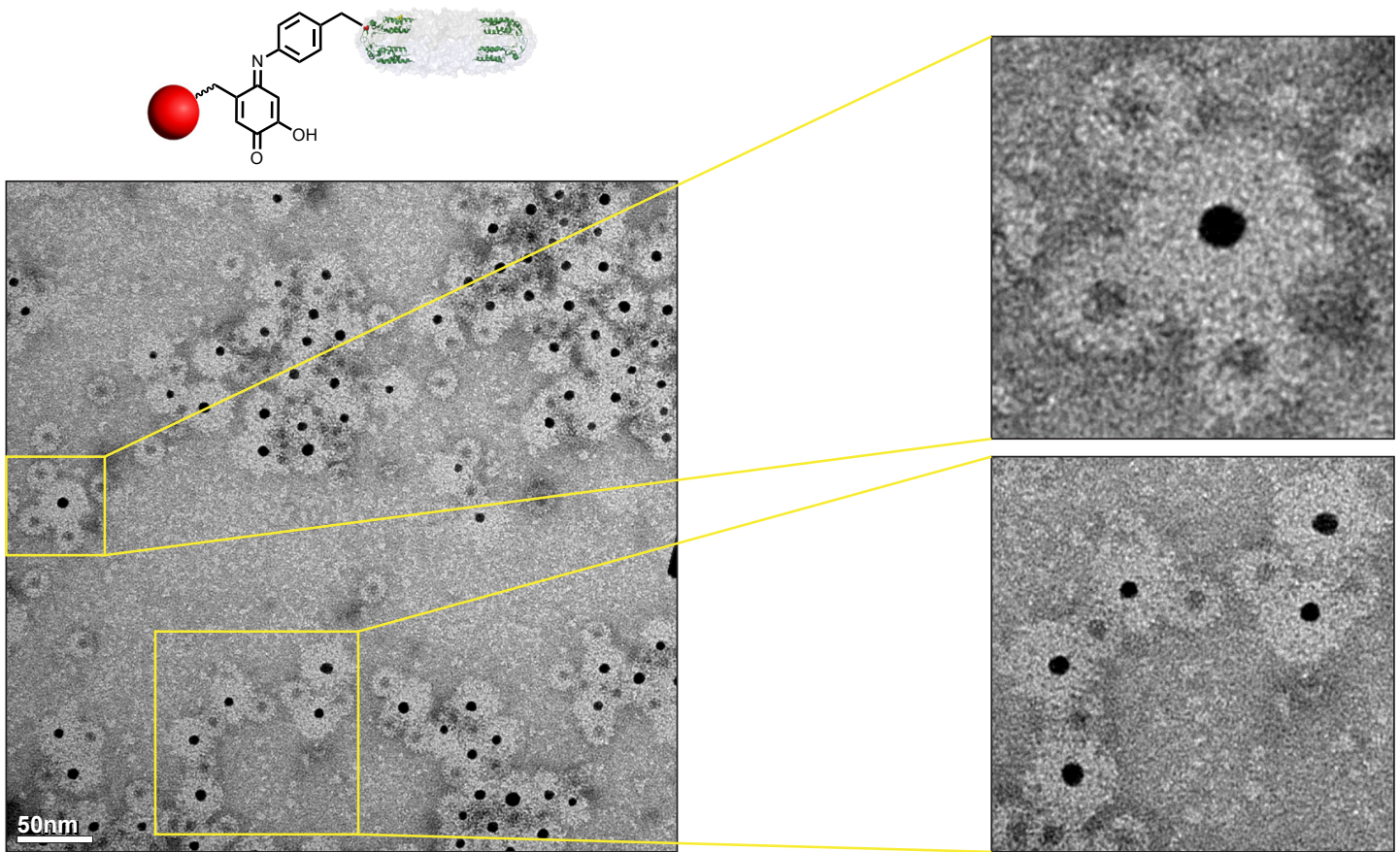

Figure S9. TEM analysis of cpTMV-AuNP conjugates. TEM suggested that no conjugation occurred in (A) the absence of tyrosinase (abTyr), (B) the absence of phenol groups, or (C) the absence of aniline-containing cpTMV. (D) cpTMV-AuNP conjugates were only formed when phenol-AuNPs, cpTMV-S65pAF, and tyrosinase were all present. Large arrays could be produced through multiple oxidative coupling reactions on a single cpTMV-S65pAF assembly. 
A

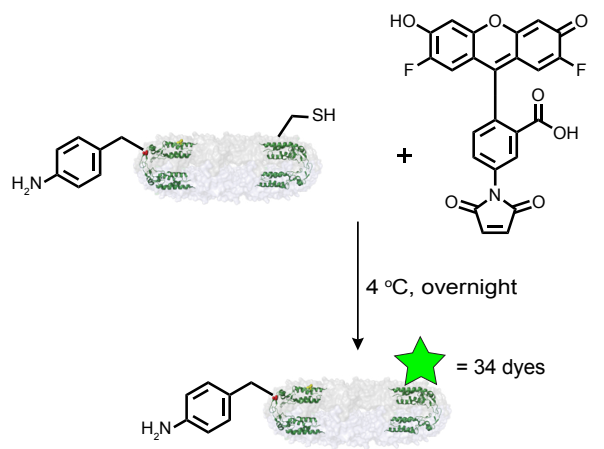

B
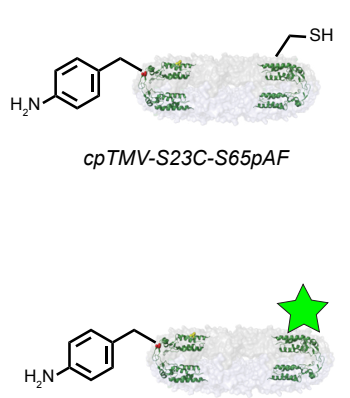

cPTMV-S23C-S65PAF-OG488
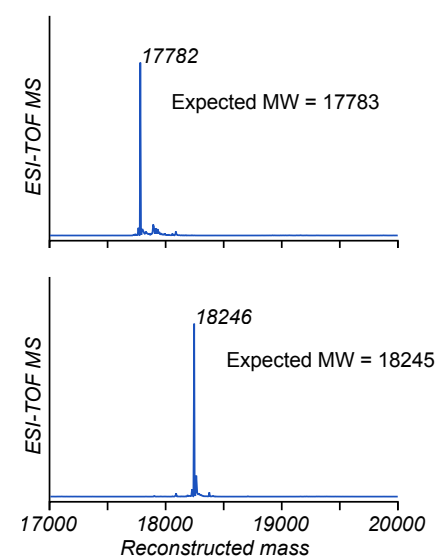

C

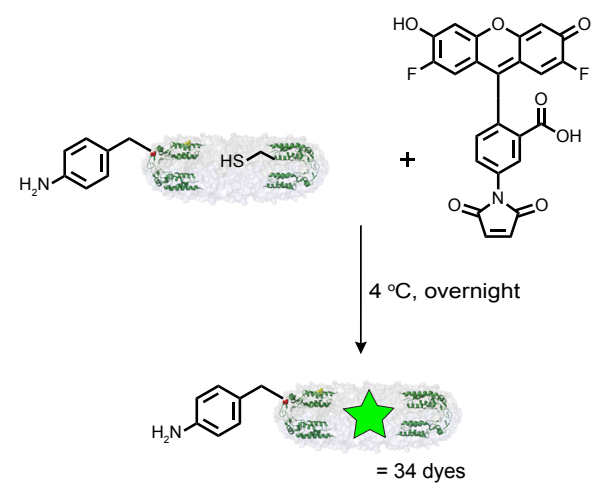

D
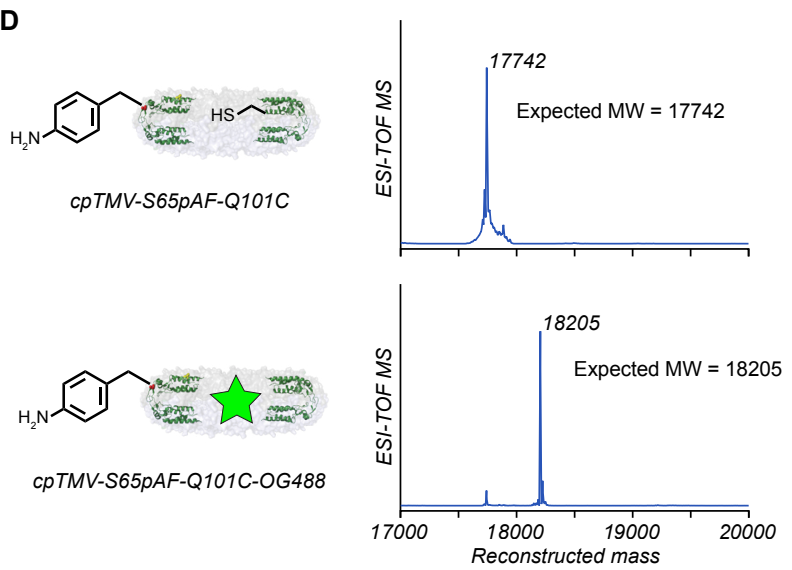

Figure S10. cpTMV-S23C-S65pAF-OG488 and cpTMV-S65pAF-Q101C-OG488 characterization by ESI-TOF LC-MS. (A) Maleimide-thiol chemistry was used to label cpTMV-S23C-S65pAF with Oregon Green 488 (OG488). (B) Full conversion of cpTMV-S23C-S65pAF to cpTMV-S23C-S65pAF-OG488 was observed. (C) Maleimide-thiol chemistry was also used to label cpTMV-S65pAF-Q101C with OG488. (D) Almost full conversion of cpTMV-S65pAF-Q101C to cpTMV-S65pAF-Q101C-OG488 was observed. 


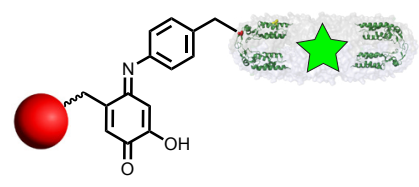

cpTMV-S65pAF-Q101C-OG488

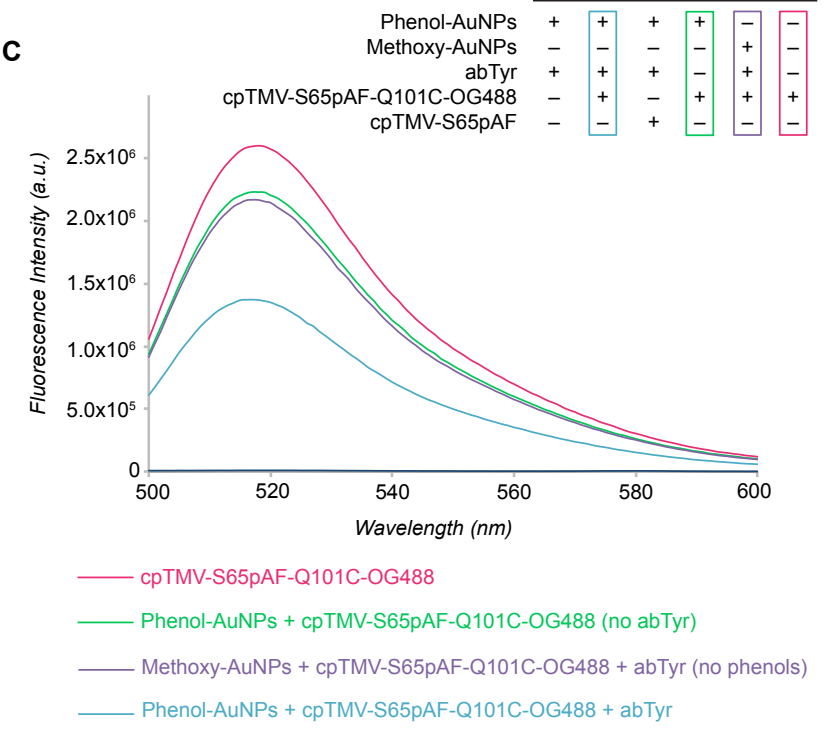

Figure S11. Fluorescent measurements of cpTMV-S65pAF -Q101C-OG488 conjugated to phenol-AuNPs. (A) Oregon Green 488 (OG488) maleimide was conjugated to cpTMV-S65pAF -Q101C (cpTMV-S65pAF with an engineered cysteine residue on the internal surface of the disks; see Figures S8, S10C, and S10D). The resulting cpTMV-S65pAF-Q101C-OG488 proteins were oxidatively coupled to phenol-AuNPs in the presence of tyrosinase (abTyr) and analyzed by (B) native gel electrophoresis and (C) fluorometry. Both characterization techniques revealed quenching of OG488 when cpTMV-S65pAF-Q101C-OG488 was conjugated to the AuNPs. Slight quenching in the presence of methoxy-AuNPs and phenol-AuNPs with no abTyr was attributed to light scattering from AuNPs in solution. Each cpTMV-S65pAF-Q101C-OG488 assembly exhibited 34 aniline moieties and 34 OG488 dye molecules. Oxidative coupling was carried out with $400 \mathrm{nM}$ AuNPs and $0.2 \mu \mathrm{M}$ (in capsid) TMV. 

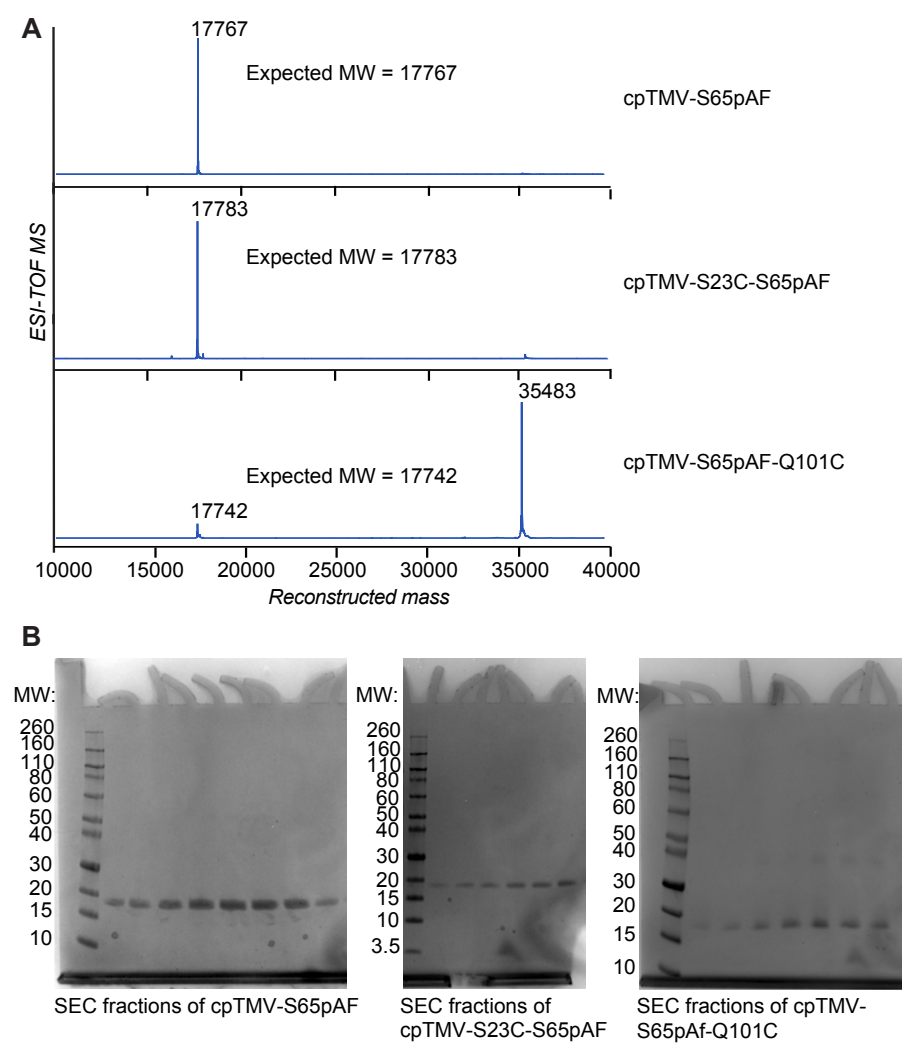

Figure S12. Characterization of purified cpTMV-S65pAF, cpTMVS23C-S65pAF, and cpTMV-S65pAF-Q101C. (A) Mass spectra for the purified proteins confirmed the expected masses. The Q101C mutant was predominantly present as a dimer due to disulfide formation between cysteines on neighboring monomers. (B) Gel electrophoresis of the purified proteins revealed successful purification. 

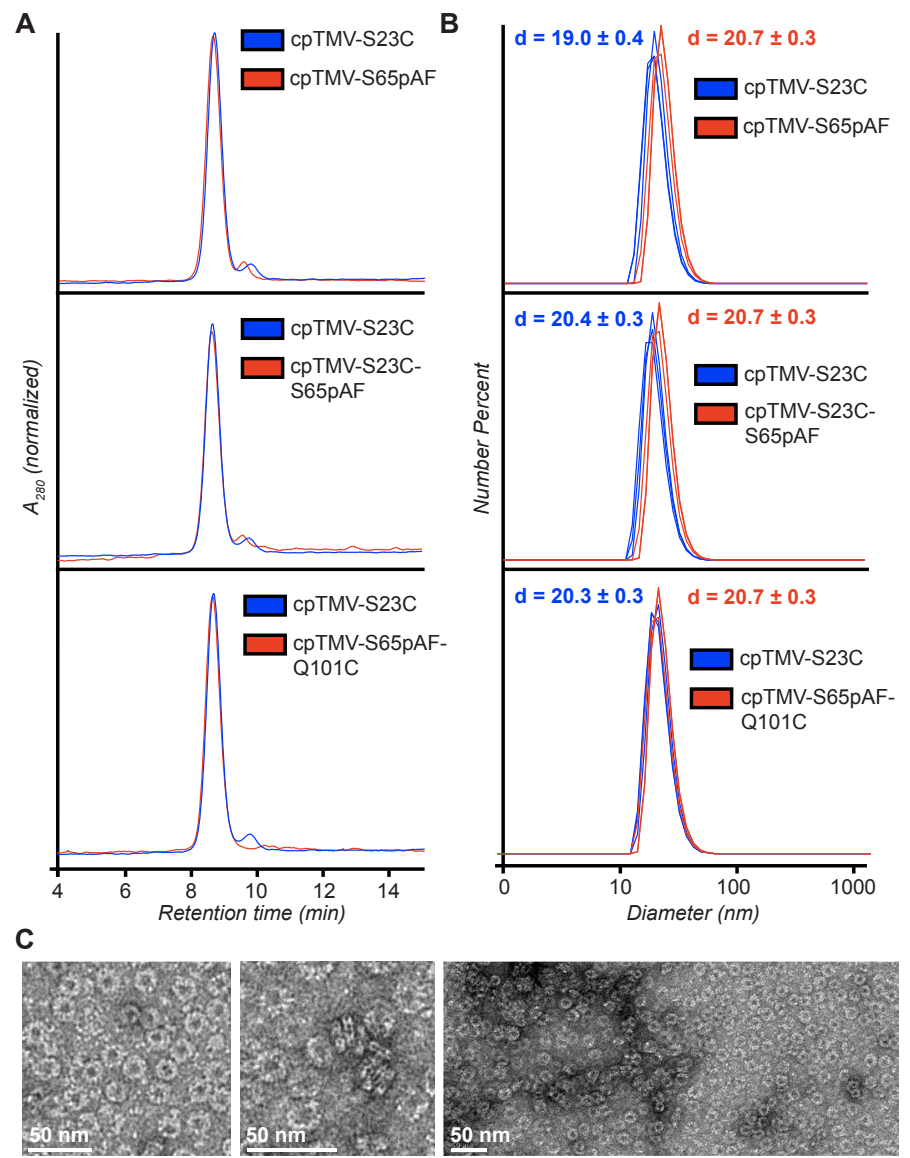

Figure S13. Characterization of cpTMV protein assembly states. A) HPLC data of cpTMV-S65pAF, cpTMV-S23C-S65pAF, and cpTMV-S65pAF-Q101C revealed disk structures similar to those of cpTMV-S23C, a protein of known structure. A retention time of 8.5 min indicated a double disk assembly state; the small peaks at $9.5 \mathrm{~min}$ indicated a small population of monomers. (B) Dynamic light scattering number percent data demonstrated consistent sizes between each cpTMV mutant and cpTMV-S23C, a protein of known double disk structure. The average diameter was calculated from intensity percent data from three replicates. (c) TEM images of cpTMV-S65pAF confirmed the double disk structure via top-down and side views of the disks. 


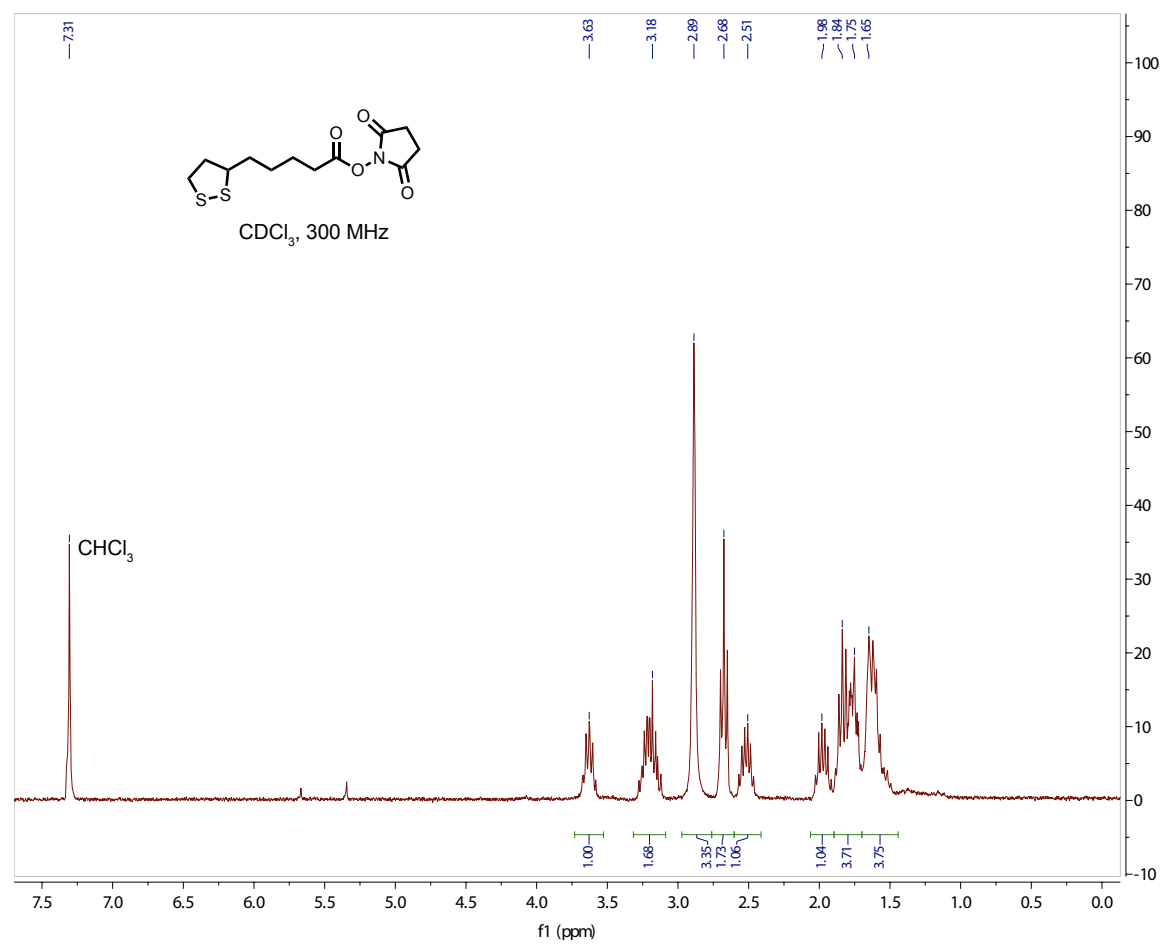

Figure S14. Characterization of lipoic acid-NHS via ${ }^{1} \mathrm{H}$ NMR. 


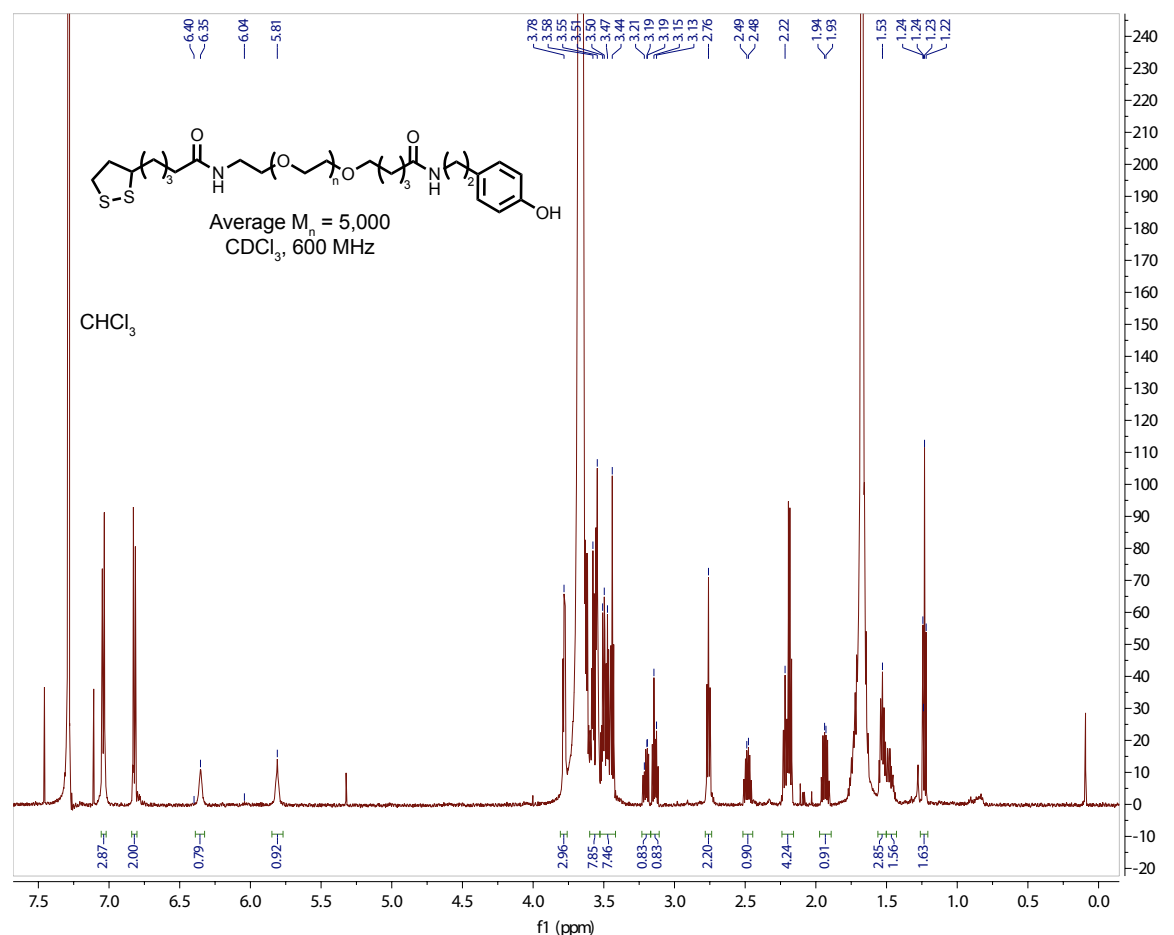

Figure S15. Characterization of thiol-PEG5k-phenol via ${ }^{1} \mathrm{H}$ NMR. 